\title{
A Case of Cervical Ectopic Pregnancy
}

\author{
JAHANARA BEGUM ${ }^{1}$, SHAMSUNNAHAR BEGUM (HENA) ${ }^{2}$, \\ ROWSHAN ARA ${ }^{3}$, SHAMIM FATEMA NARGIS ${ }^{4}$
}

\begin{abstract}
:
Cervical ectopic pregnancy is the implantation of a pregnancy in the endocervix ${ }^{1}$. Such pregnancy typically aborts within the first trimester, if it is implanted closer to the uterine cavity called cervico isthmic pregnancy it may continue longer ${ }^{2}$. Cervical pregnancy accounts for less than 1\% of all ectopic pregnancies, with an estimated incidence of one in 2500 to one in 18000 3-5. Though the pregnancy in this area is uncommon but possibly life threatening condition due to risk of severe hemorrhage and may need hysterectomy. Early detection and conservative approach of treatment limit the morbidity and preserve fertility.
\end{abstract}

A 26 years lady diagnosed as a case of cervical ectopic pregnancy and managed conservatively successfully with adjunctive techniques like cervical artery ligation and cervical temponade to control haemorrhage. The case is reported here for its relative rarity.

Key Words: Cervical Ectopic, Intractable bleeding, Cervical artery ligation, cervical temponade.

\section{Introduction:}

In ectopic pregnancy the fertilized ovum becomes implanted in a site other than normal uterine cavity. It is the consequence of an abnormal implantation of the blastocyst. Worldwide incidence of ectopic pregnancy is $3-4 \%$ but the incidence is rising. In some studies the incidence reported as high as 19.7 ectopic pregnancies for $1000^{6}$. It is one of the leading cause of maternal mortality. About 95-98\% of ectopic pregnancy occur in fallopian tube. Ectopic pregnancy in cervix is rare but occasionally encountered in obstetric practice. The treatment options depend on patient's condition, gestational age, fertility status ${ }^{7}$. Cervical ectopic can easily be misdiagnosed as a threatened abortion and rupture may lead to potentially fatal bleeding. Fatal hemorrhage also occurs if dilatation and curettage (D $\& C)$ is attempted in such a case.

So obstetrician must suspect cervical ectopic pregnancy in women with first trimester vaginal bleeding in order to permit early diagnosis and fertility saving treatment ${ }^{8}$.

\section{Case Reports:}

Mrs. R, a 26 years primigravida, attended a private clinic with the complaints of amenorrhoea for 5 weeks following ovulation induction by clomiphene for subfertility. Regarding her menstrual history she was a regularly menstruating woman with average flow and duration. She was married for 5 years, having no issue and no history of MR or D and C. She had no relevant family history. On general examination she was mildly anaemic, normotensive. On per abdominal examination nothing abnormal was detected. Her serum ßhCG was 12,785mIU/ml. Ultrasonography revealed single cervical alive pregnancy of 6 weeks size (fig-1) with tiny myoma on the post wall of the fundus. Repeat USG after 15 and 30 days revealed 8 weeks (fig:2) and 10 weeks (fig-3) cervical live pregnancy. She refused termination of the pregnancy. At her 11 weeks of pregnancy she started P/V bleeding and USG revealed 11 weeks missed abortion within the cervix. Bleeding became more severe with lower abdominal pain and expulsion of the foetus occured but placenta remained within the cervical canal. For severe bleeding an attempt was made to remove the placenta by curettage but she started intractable bleeding for which descending cervical artery on both sides were ligated and tight vaginal pack was given. At the same time patient was managed by oxytocin drip , blood transfusion, misoprostol 600 microgram per rectally. Also 50 mg methotrexate (MTX) was given intramuscularly. Second dose of MTX was given on 7th post-operative day and patient was discharged on $8^{\text {th }}$ post-opertive day with slight per vaginal bleeding continuing. After 1 month she came for follow up, having no complaints and found alright.

\footnotetext{
1. Assistant Professor

2. Professor

3. Assistant Professor

4. Assistant Professor

Sir Salimullah Medical College (SSMC), Midford, Dhaka.
} 


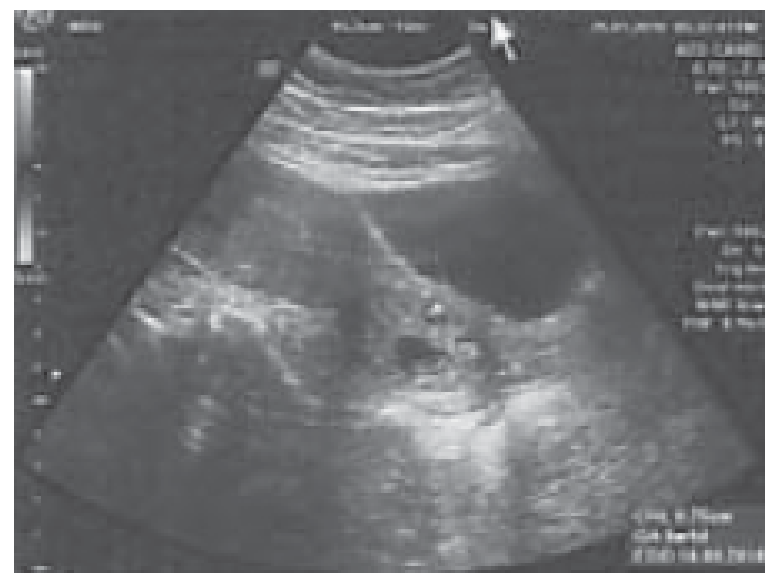

Fig.1: The USG View of 6 Weeks Cervical alive Pregnancy.

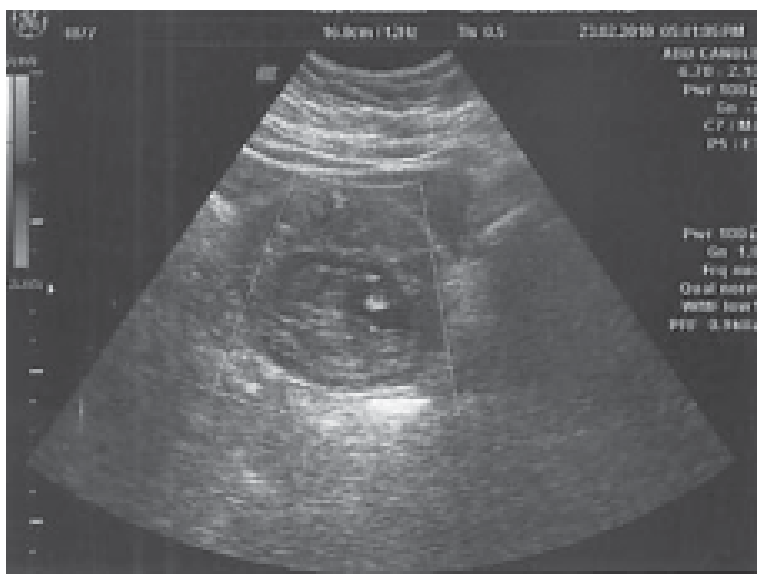

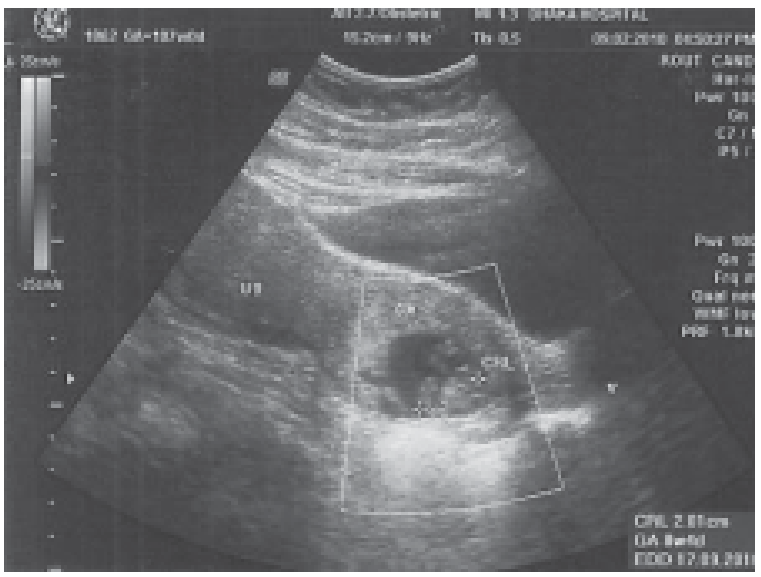

Fig.2: A Color Doppler View of 8 weeks alive Pregnancy.

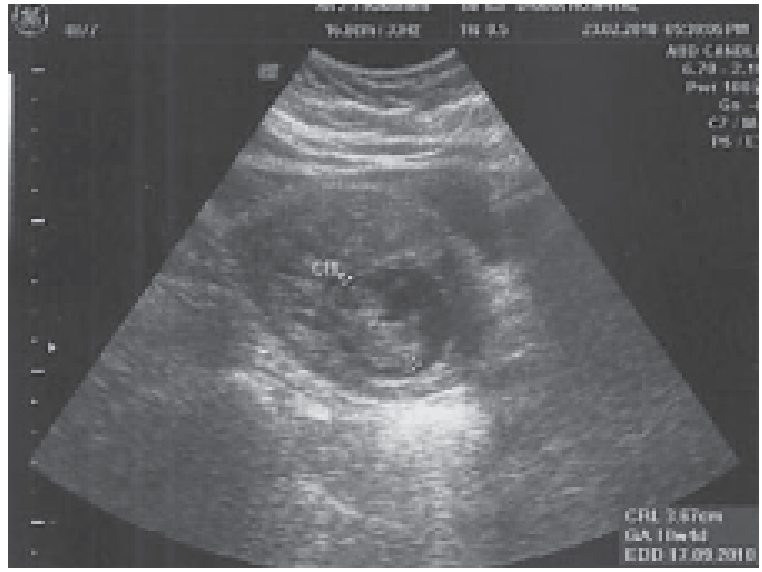

Fig.-3: Color Doppler \& USG view 10 weeks 4 days of cervical alive pregnancy

\section{Discussion}

Although the exact etiology of cervical ectopic pregnancy was unknown, but the probable predisposing factors are accelerated migration of fertilized ovum to the cervical canal before it is capable of nidation ${ }^{7-9}$, damage of the endocervical canal due to previous instrumentation e.g prior dilatation and curettage $^{10,11}$, PID, anatomical anomalies (myomas, synechiae), use of intrauterine device, in vitro fertilization (IVF) ${ }^{12,13}$. Diethylstilbestrol exposure is the other factor.

Classically these patiens present with first trimester per vaginal bleeding ${ }^{7}$, with or without abdominal pain ${ }^{8}$, pelvic pain ${ }^{7}$, hemorrhagic mass ${ }^{3,4}$, a gestational sac with the presence of a embryo with or without cardiac activity ${ }^{3,4}$. P/S Examination reveales a partially open external os, bloody mucoid discharge from the cervix, a visible cervical lesion, bulky bluish cervix with a fluctuant purple or blue mass; or cervix may be distended or edematous in appearance ${ }^{6}$. In this case vaginal examination revealed soft cervix that was disproportionately enlarged compared with the uterus and profuse hemorrhage occured on manipulation of the cervix. Uterus is usually 6 to 8 weeks size in cervical pregnancy, with unremarkable adnexa or tenderness may be present ${ }^{7}$. For accurate diagnosis, sonographer must be familiar with distinctions between cervical pregnancy, cervical abortion and early intrauterine pregnancy ${ }^{7}$.

In the past, the diagnosis of cervical pregnancy was made primarily at the time of histological analysis of hysterectomized uterus. Cervical pregnancy was first described in 1817 and named as such in $1860^{14}$. In 1911, Rubin proposed the pathological criteria for 
the diagnosis of cervical ectopic pregnancy. These were cervical glands must be present opposite the placental attachment, the attachment of placenta to the cervix must be intimate, the whole or a portion of the placenta must be situated below the entrance of the uterine vessels or below the peritoneal reflection of the anterior and posterior surface of the uterus and no fetal elements must be present in the corpus uteri $^{7}$. The first reported case of cervical ectopic was diagnosed by USG in $1978^{15}$. In 1993 Timor-tritsch ${ }^{16}$ proposed some stringent criteria: the placenta and entire chorionic sac containing the live pregnancy must be below the internal os, Cervical canal must be dilated and barrel shaped. Gestational sac in cervical abortion is often crenated ${ }^{17}$, but in cervical pregnancy it become round or oval and demonstrate some evidence of a fetus or yolk sac. Internal os invariably remain dilated in a cervical abortion and completely closed in a cervical pregnancy. Endometrial cavity in a cervical abortion often show a dense echogenic mass representing a mixture of blood and products of conception, body of uterus being larger than in non-gravid state owing to recent loss of the intrauterine sac, while in the cervical pregnancy, prominent endometrial echo caused by decidual reaction usually seen ${ }^{18}$. In 1996, Jurkovic et ${ }^{19}$ proposed "sliding sign"detected on TVS examination, when gentle pressure is applied on the cervix with the probe, the gestatinoal sac of an abortus slides against the endocervical canal, this sliding motion usually could not be found in implanted cervical pregnancy. Color Doppler can show peritrophoblastic blood flow from an active vascular supply to the conceptus. The nonviable sac transiently passing through the cervix, will not have any peritrophoblastic flow, as it separated from its vascular supply?

Traditionally these pregnancies were managed surgically. Due to anatomical location, surgery is notoriously hazardous. Consequenty, many women with this type of problem underwent hysterectomy. Now there has been significant shift from such an approach to more conservative treatment modalities. Due to improved access to TVS scanning and rapid assay of BhCG, most ectopics, including cervical pregnancies are now detected earlier. As a result of diagnosis earlier in gestation, women have lower serum BhCG levels and are clinically more stable, therefore can be offered conservative management ${ }^{20}$. Use of anti metabolite MTX has facilitated the medical management. Conservative treatment is expectant and medical. Expectant management is a 'wait and see' approach. Medical management in the form of systemic or intra-amniotic MTX, with or without intra-amniotic potassium chloride administration ${ }^{21}$. Criteria for conservative treatment are, patient should be hemodynamically stable, have no hemoperitoneum on TVS scanning, have normal kidney and liver function. Additional specific requirement for expectant management are no fetal cardiac activity, initial BhCG level is low and subsequently decreasing. It is advocated that a single dose of systemic MTX $\left(50 \mathrm{mg} / \mathrm{m}^{2}\right)$ as first-line management for cervical ectopic pregnancies with no visible cardiac activity ${ }^{22}$. Serum ßhCG levels were measured on day 1, 4 and 7 with day 1 being the day of the first injection of MTX. If serum BhCG level drop is by more than $15 \%$ between day 4 and 7 , this deemed acceptable. Serum BhCG level should be checked weekly until $<10 \mathrm{IU} / \mathrm{L}^{23}$. Cervical pregnancies with fetal cardiac activity, initial treatment should ideally be local MTX or potassium chloride injection with or without interval curettage. Multipledose, alternate days systemic MTX is an alternative treatment $(1 \mathrm{mg} / \mathrm{kg}$ on days 1,3 and 5$)$ with folinic acid rescue $(0.1 \mathrm{mg} / \mathrm{kg}$ on day 2,4 and 6$)$. For Intraamniotic administration16 gauge double lumen oocyte collection needle can be introduced under TVS guidance into the amniotic sac and TVS is repeated on alternate days to check viability. If foetal cardiac activity persisted, intra-amniotic potassium chloride is injected. The amniotic sac must be kept intact to avoid substantial bleeding. Cause of MTX failure are presence of foetal cardiac activity, initial serum ßhcg level $>10,000 \mathrm{IU} / \mathrm{L}$, gestational age $>9$ weeks, crownrump length $>10 \mathrm{~mm}^{24}$. If the treatment failed with both single and multiple dose MTX, intra-amniotic injection of potassium chloride, will be successful.

Surgical treatments are conservative surgery and definitive surgery. Conservative surgery is curettage but it may be combined with other mechanical techniques to reduce blood supply. Reduction of blood supply by cervical cerclage, ligation of the cervical arteries, uterine artery ligation, internal iliac artery ligation ${ }^{7}$ and angiographic embolization of the cervical, uterine or internal iliac arteries. These procedure have recently been used primarily as "rescue" therapy when, profuse bleeding follows. Intracervical vasopressin has also been used to minimize bleeding. Curettage is used to remove sonographically nonviable pregnancy after 
chemotherapy. Some believe that curettage is necessary to reduce massive hemorrhage after trophoblastic shedding from the atonic cervix that

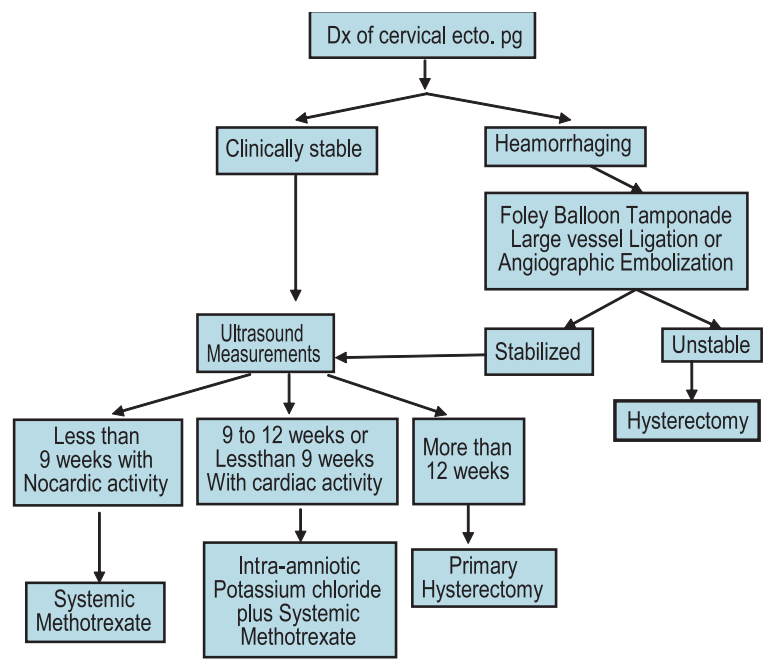

Fig.-4: Suggested treatment algorithm: cervical ectopic pregnancy.

occurs as a metabolic effect of MTX 24,25 .

Cervical or vaginal packing was most commonly used to apply direct pressure on the bleeding site. Use of a Foley catheter, with inflation of the balloon in the cervical canal is more effective in achieving hemostasis than packing ${ }^{26}$. Definite surgery is hysterectomy, indication of which are intractable heamorrhage, second or third trimester cervical pregnancy, no desire for fertility ${ }^{7}$.

Outcome of conservative treatment of cervical ectopic is promising. A review of English literature from 1911 to 1994 found 37 pregnancies in 29 women after conservative treatment of cervical pregnancy ${ }^{27}$. Of them 34 pregnancy were intrauterine, 2 were tubal ectopic and 1 was a repeated cervical pregnancy. Early ultrasound examination in a subsequent pregnancy may be advisable to detect a recurrent ectopic pregnancy because USG can identify more than $80 \%$ of cervical pregnancies when it is suitable for medical or minimally invasive therapy ${ }^{8}$. Outcome of most of pregnancies after a cervical ectopic will lead to term deliveries but there is possibility of preterm labour in such cases ${ }^{7}$.

\section{Conclusion:}

As cervical ectopic can easily be misdiagnosed as threatened spontaneous abortion, the distinction is extremely important, as the treatment methods differ significantly. Simple speclum examination is found to be more informative and less likely to result in bleeding than bi-manual examination.

It is important to assess both the patient and the services available while making treatment decisions. Methotrexate is a reasonable first line therapy. It is easy to administer and can be given in any hospital. Gynecologist should be highly aware of these types of cases and should be skilled enough in the diagnosis and management of this life threatening condition.

\section{Reference:}

1. Lin EP, Bhalt S, Dogra VS. Diagnostic clues to ectopic pregnancy. Radiographics 2008; 28(6): 1661-75.

2. Avery DM, Wells HA, Harper DM. Cervicoisthmic corporeal pregnancy with delivery at term: a review of the literature with a case report Obstet Gynaecol Surv. 2009; 64(5): 335-44.

3. Cepni I, Ocal P, Erkan S, Erzik B. Conservative treatment of cervical ectopic pregnancy with transvaginal ultrasound guided aspiration and single-dose methotrexate. Fertil Steril 2004; 81(4): 1130-1132

4. Benson C B. Doubilet P M. Strategies for conservative treatment of cervical ectopic pregnancy. Ultrasound Obstet Gynecol 1996; 8: $371-372$

5. Ushakov F B. Elchalal U, Aceman P J. Schenker J G. Cervical pregnancy: past and future. Obstet Gynecol Surv 1997; 52: 45-59

6. Tenor JL. Ectopic pregnancy. Am Fem Physicain. 2000; 61(4): 1080-88.

7. leeman LM, Wendland CL. Cervical Ectopic Pregnancy, Diagnosis with endovaginal Ultrasound Examination and successful Treatment With Methotrexate, Arch Fam Med. 2000; 9: 72-77.

8. Michele G. sullivan, Elsevier Global Medical News, Cervical Ectopic Pegnancy Easy to Miss, ACEP News, February 2010.

9. Studdiford WE. Cervical pregnancy ; A partial review of the literature and a report of two probable cases, Am J Obstet Gynecol 1945; 49 : 169-185 
10. Shinaganwa S, Na gayama M. Cervical Pregnancy as a possible sequela of of induced abortion. Am J Obstet Gynecol . 1969;105: 282-284

11. Rothe Dj, Birnbaum SJ. Cervical pregnancy. Obstet Gynecol 1973;42:675-680

12. Ginsburg ES, Frates MC, Rein Ms, et al. Early diagnosis and treatment of Cervical Pregnancy in an in vitro fertilization program. Fertill Steril. 1994;61:966-969

13. Weyerman PC, Verhoeven ATM, Alberda AT. Cervical Pregnancy after in vitro fertilization and embryo transfer. Obstet Gynecol. 1989;161:1145-1146

14. Marcovici I, rosenzweig BA, Brill Al, Khan M, Scommgna A. Cervical Pregnancy. Obstet Gynecol Surv.1994; 49:49-55

15. Raskin MM,. Diagnosis of cervical Pregnancy by ultrasound. A case report. Am J Obstet Gynecol 1978;130;234-235.

16. Timor-Tritsch IE, Monteagurdo A, Mandeville $E O$, et al Successful management of viable cervical pregnancy by local injection of methotrexate guided by transvaginal ultersonography. Am J Obstet Gynecol. 1994;17:737-739

17. Frates MC, Benson CB, Doubilet PM, et al. Cervical ectopic pregnancy. Radiology. 1984;191:773-775.

18. Vas W, Suresh PL, Tang-Brton et al. Ultrasonographic differentiation of cervical abortion from cervical pregnancy, J Clin ultrasound. 1984;12:553-537.
19. Jurkovic D, Hacket E Campbell S. Diagnosis and tretment of early Cervical pregnancy. Ulterasound Obstet Gynecol. 1996;8:373-380

20. Qasim SM, Bohrer MK, Kemmann E. Recurrent Cervical pregnancy after assisted reproduction by intra-fallopian transfer. Obstet Gynaecol 1996; 87:831-832.

21. Condous G, Okaro e, Khalid A, Lu C, Van Huffel $S$, Timmerman D, Boure t. A prospective evaluation of a single-visit strategy to manage pregnenies of unknown location. Hum Reprod 2005;20;1398-1403

22. Kirk E, Condous G, Haider Z, Syed A, Ojha K. and Bourne $\mathrm{T}$. The Conservative management of cervical ectopic pregnancies. Ultrasound Obstet Gynecol. 2006; 27(4): 430-7.

23. Stovall TG, Ling FW. Single dose methotrexate: an expanded clinical trial. Am J obstet Gynecol 1993; 168: 1759-1765

24. Hochner-Celnikier D, Ron M, Goshen R, Zacut D, Amir G, Yagel S. Rupture of etopic Pregnancy following disappearance of serum beta subunit of hCG. Obstet Gynecol 1992; 79:826-827

25. Hung TH, Shau WY, Hsieh TT, Hsu JJ, Soong $Y K$, Jeng CJ Prognostic factors for an unsatisfactory Primary Methotrexate treatment of Cervcal Pregnancy: a quantitave review. Hum Repod 1998;12:2636-2642

26. Msogitis S, Pilalis a, Daskalakis G, Papantoniou $\mathrm{N}$, Antsaklis A. Management of early viable cervical ectopic Pregnancy: results of Conservative treatment. Radiology 1994: 191:773-775

27. Ushakov FB, Elchalal U, Aceman PJ, Schenker JG. Cervical Pregenancy: past and future. Obstet Gynecol Surv. 1996;52:45-59. 